\title{
SOIL INCORPORATION OF THIOCARBAMATE HERBICIDES
}

\author{
J. R. van Diepen \\ Stauffer Chemical Company, New York City, U.S.A.
}

Summary

The placement of herbicides into the top few inches of soil is a relatively new concept in weed control. The standard method of soil-incorporating a thiocarbamate herbicide is to mechanically mix it uniformly into the soil. Subsurface and irrigation applications are other methods of placing this class of chemical into the soil. Moisture, soil type, temperature and micro-organisms are environmental factors that can affect the activity of a herbicide. Soil incorporation reduces the risk of surface loss of thiocarbamates and certain other herbicides. Another advantage of soil incorporation is that it places the chemical in the weed seed zone, where it will inhibit weed seed germination and seedling development.

\section{INTRODUCTION}

From a historical standpoint, the placement of herbicides into soil is a relatively new concept in the application of herbicides. In the late 1950s and early $1960 \mathrm{~s}$, Stauffer Chemical Company pioneered soil incorporation of selective pre-emergence herbicides. These herbicides, known specifically as thiocarbamate herbicides, such as EPTC, vernolate, and pebulate, were the forerunners of herbicides that must be soil-incorporated for maximum herbicidal activity.

The above development was followed by another discovery by Stauffer Chemical Company in the mid 1960s - i.e., the application of selective herbicides in irrigation water. During this period, research personnel of the United States Department of Agriculture at Stoneville, Mississippi, pioneered the soil subsurface placement of selective herbicides.

Because of these discoveries, placement of herbicides into soil has become very popular in many countries. This is due to the fact that soil incorporation offers many advantages, which will be brought out later in the paper. This paper will also deal with methods of placing thiocarbamate herbicides into the soil and the environmental factors that can affect the activity of this class of herbicide.

\section{METHODS OF PLACING THIOCARBAMATE HERBICIDES INTO THE SOIL \\ STANDARD SOIL INCORPORATION}

The standard method of soil incorporation is accomplished by mechanically mixing a herbicide uniformly into the top few inches of soil. Various implements are used to incorporate thiocarbamate herbicides. The type of equipment used is dependent on such factors as soil type, soil tilth, and cultural practices. For example, discs and power-driven rotary tillers should be used in medium to heavy soils; harrows and ground-driven rotary tillers may be used in light soils of good tilth when operated at speeds of 6 to $\varepsilon \mathrm{mph}$. 
The disc operated at 4 to $6 \mathrm{mph}$ is the most popular means of soil incorporation (pre-plant broadcast application) and is generally followed in the same operation by a spike-tooth harrow. On light soils one discing is normally required; however, a second discing (at right-angles to the first) is often needed, especially in heavy, cloddy soils to mix the chemical more thoroughly into the soil. Discs are generally set to cut 3 to 6 in. deep in ordet to concentrate the chemical in the upper 2 to 4 in. If incorporated deeper, the chemical may be diluted too much and weed control will not be satisfactory. Since most weed seeds germinate in the top few inches of soil, this is the best herbicide placement position for maximum weed seedling exposure. Deep incorporation is only needed for control of weed species that have rhizomes, such as couch (Agropyron repens), or other underground vegetative parts located at deeper soil depths.

\section{Subsurface Application}

The subsurface method of application pertains to the precision placement of herbicides beneath the soil surface. This is accomplished by injection shanks and covered sweeps. Soil injection shanks inject a thin ribbon of liquid 1 to 2 in. below the soil surface at spacings of 3 to 6 in. The shanks are usually made of steel $1 / 4 \mathrm{in}$. thick by $2 \mathrm{in}$. wide, and are mounted in a staggered position to allow clods and trash to pass between them. With covered sweeps, a thin band of chemical can be placed 2 to $5 \mathrm{in}$. below the soil surface. Covered sweeps are made by welding a plate to the top of a standard cultivator sweep, and mounting a wideangle spray nozzle under the plate.

Generally, subsurface applications are made at planting time by mounting covered sweeps immediately ahead of the planters or by mounting injection shanks either immediately ahead or immediately behind the planter units.

\section{IRRIGATION APPLICATION}

Certain herbicides of the thiocarbamate class, such as EPTC, can effectively control weeds when applied in the irrigation water. Depending on the crop involved, application can be made through (a) overhead irrigation systems, (b) furrow irrigation systems, and (c) flood irrigation systems. In flood and furrow irrigations, $a^{\prime}$ herbicide can be metered at the point where the water enters the field. With overhead irrigation, it is metered either or. the suction side or the discharge side of the pump. In every case, it can be metered into the water source, such as head ditches, stand pipes and irrigation lines.

Irrigation applications are generally made after planting and prior to weed emergence They may also be applied to established stands of crops such as lucerne, citrus and deciduous fruits.

\section{EFFECT OF ENVIRONMENTAL FACTORS ON THE ACTIVITY OF THIOCARBAMATES}

MoIsture

For most effective and consistent results, thiocarbamate herbicides should be applied to a relatively dry soil surface and mechanically incorporated into the upper 2 to 4 in. of soil immediately following application. The herbicide should also be applied to a well-worked soil that is dry enough beneath the surface to permit good incorporation. Herbicides of this class are volatile, especially from soil particles which contain ex- 
cess moisture. When these herbicides are not incorporated and come in contact with moist soil, large amounts of the chemical are rapidly lost owing to volatilization. Thiocarbamates are readily adsorbed by dry soil.

\section{SoIL TYPE}

Soil type affects leaching and the lateral movement of thiocarbamates in the soil profile. Studies have shown that leaching and lateral movement decreased as the clay content and organic matter content increased. Little, if any, downward leaching occurs in peat soils, in contrast to sandy soils where movement is considerable.

These chemicals are able to move in the soil as a vapour. This is important from the standpoint of uniformity of distribution, which increases the chances of effective weed control.

\section{TEMPERATURE}

Temperature interacts with the vapour pressures and the water solubilities of thiocarbamates. The higher the temperature, the greater the volatility of the chemical from wet soil surfaces. Increasing the temperature, when applied to dry soil, causes very little increase in loss of the chemical because it becomes adsorbed on dry soil particles. The water solubility of thiocarbamates increases with decreased temperature. As a result, movement in the soil increases when soil temperatures are low.

\section{MICRO-ORGANISMS}

Studies have shown that thiocarbamates disappear much faster in nonsterilized soils than in sterilized soils. This indicates microbial breakdown. The slight disappearance of these compounds in sterilized soil is due to chemical (hydrolysis) breakdown. $\mathrm{pH}$ of the soil has no direct effect on the activity of thiocarbamates.

\section{ADVANTAGES OF SOIL INCORPORATION}

Since the standard method of soil incorporation is the most frequently used method of placing herbicides into soil, this method is used to illustrate certain advantages of mixing a thiocarbamate herbicide into the soil in order to obtain maximum weed control. The advantages are:

(1) Soil incorporation reduces the risk of surface loss of a herbicide, by vaporization, photodecomposition, wind erosion, or by being washed away by heavy rains.

(2) When a herbicide is soil-incorporated, it is not dependent on rainfall to carry it into the weed seed zone. The chemical is already in position to inhibit weed seed germination and seedling development.

(3) Incorporation places the herbicide where there is likely to be more moisture for seed germination, and chemical absorption by the germinating weed seads and weed seedlings. The chemical is at the site of uptake.

(4) Incorpcrating a herbicide ahead of planting simplifies the spring work as the work load is reduced at planting time.

(5) Soil incorporation destroys by mechanical means existing weed seedlings which may be present in the field.

(6) Cultivation following treatment does not adversely affect the performance of a soil-incorporated herbicide. 